\section{Turnbull Lectureship Bestowed on Nowick}

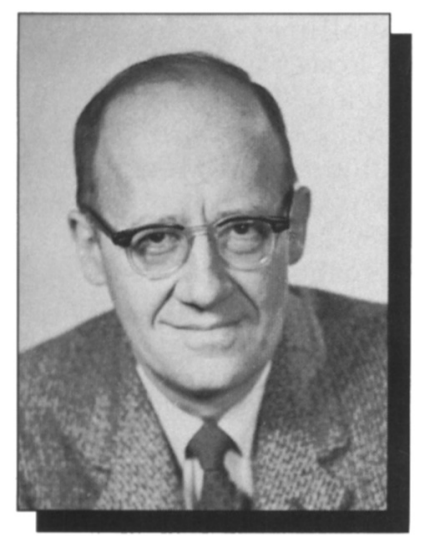

Arthur S. Nowick, Henry Marion Howe Professor Emeritus of Metallurgy and Materials Science at Columbia University in the Henry Krumb School of Mines, has been selected as the 1994 recipient of the David Turnbull Lectureship "for pioneering work in anelastic and dielectric behavior, in fast ion conductors, and in amorphous alloys, and for his excellence in teaching and writing." The David Turnbull Lectureship recognizes the career of a scientist who has made outstanding contributions to understanding materials phenomena and properties through research, writing, and lecturing, as exemplified by David Turnbull.

Nowick has made major contributions to the understanding of defect states in solids, and he has educated and encouraged young scientists and engineers. He has a highly interdisciplinary approach to research in materials. While training as a physicist, he launched his research career with the study of point defects and dislocations in metal alloys and their role in diffusion in the early 1950s. He soon expanded his treatment of defects to the alkali halides, including work on color centers and impurity and deformation effects on ionic conductivity. His later research expanded into transport and relaxation processes in ceramic oxides, glasses, and polyimides.

Nowick is particularly well-known for his work on internal friction and anelasticity, which culminated in a definitive treatise on this subject, Anelastic Relaxation in Crystalline Solids (1972, coauthored with B.S. Berry). In this and other publications, he developed a comprehensive theory of anelastic and dielectric behavior caused by point defects and their interactions. He was one of the early pioneers in the use of internal friction as a tool to study the dynamics of dislocation motion. He also developed the use of anelasticity to study alloy phenomena, particularly atomic mobility in solid solutions. He was the first to demonstrate that quenching-in of vacancies could produce enhanced atom movement.

Nowick developed internal friction and anelasticity into a form of mechanical spectroscopy. He taught the next generation how to use the technique and how to formulate the important questions that the method could address.

Nowick has long been active in studying defect mobility in ionic crystals, beginning with the alkali halides in the 1950 s. His research has included studies of the defect structure of quartz crystals, of oxides which behave as oxygen-ion conductors (especially ceria and its solid solution), and of oxides of the perovskiterelated structure that are principally protonic conductors.

His work with graduate students on ceria-based oxide ion and perovskitebased hydrogen-ion fast ion conductors has stimulated the investigation of new fast ion and mixed ionic-electronic conductors, has clarified the roles of dopants and chemical composition in forming defect complexes and influencing transport, and has contributed to the understanding of interfacial kinetics at electrode-gas interfaces.

While at IBM, as head of the Metallurgy group in the mid-1950s to mid1960 s, Nowick with S. Mader developed the vapor-quenching technique for the production of metastable alloys, particularly amorphous alloys. This work first demonstrated that ferromagnetism could occur in an amorphous material, and this discovery has now developed into an active field.

Nowick is a superb teacher, making complex concepts accessible to novices and instilling in them an appreciation for the beauty of the field. In 1988 he received the Great Teacher Award of Columbia University. He is able to guide students to develop their unique strengths without attempting to oversee every move. His publications and lectures are classics of exposition, expressed clearly and exactly, and they continue to be sources of inspiration.

Nowick received his $A B$ degree in physics from Brooklyn College in 1943, and his $\mathrm{AM}$ and $\mathrm{PhD}$ degrees in physics from Columbia University in 1948 and 1950 , respectively. He was an instructor at the University of Chicago from

\section{"ULTRA THIN"}

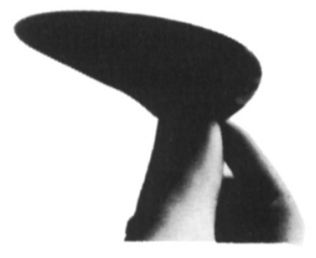

$$
2-4 \mu T H I N
$$

silicon membranes!

\author{
Available in 2 and 3 " \\ diameters, these double side \\ polished elastic membranes \\ combine a balance of \\ thinness, parallelism and \\ flatness heretofore not \\ available in single crystal \\ silicon.
}

\section{Applications include: - micromachining -X-ray lithography -particle beam focusing -stress diaphragms -bonded silicon}

\section{All processing from crystal} growth to polishing, is done on VSI premises.

Whether your requirements are in research or production quantities, let's talk about putting these membranes to work for you.

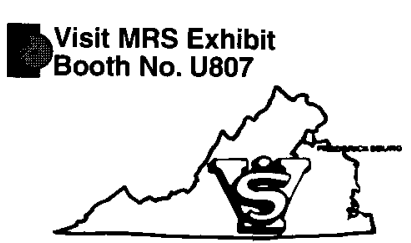

VIRGINIA SEMICONDUCTOR, INC.
1501 Powhatan Street
Frederickburg, VA 22401
Phone (703) 373-2900
Telex 9102506565
Fax (703) $371-0371$ 


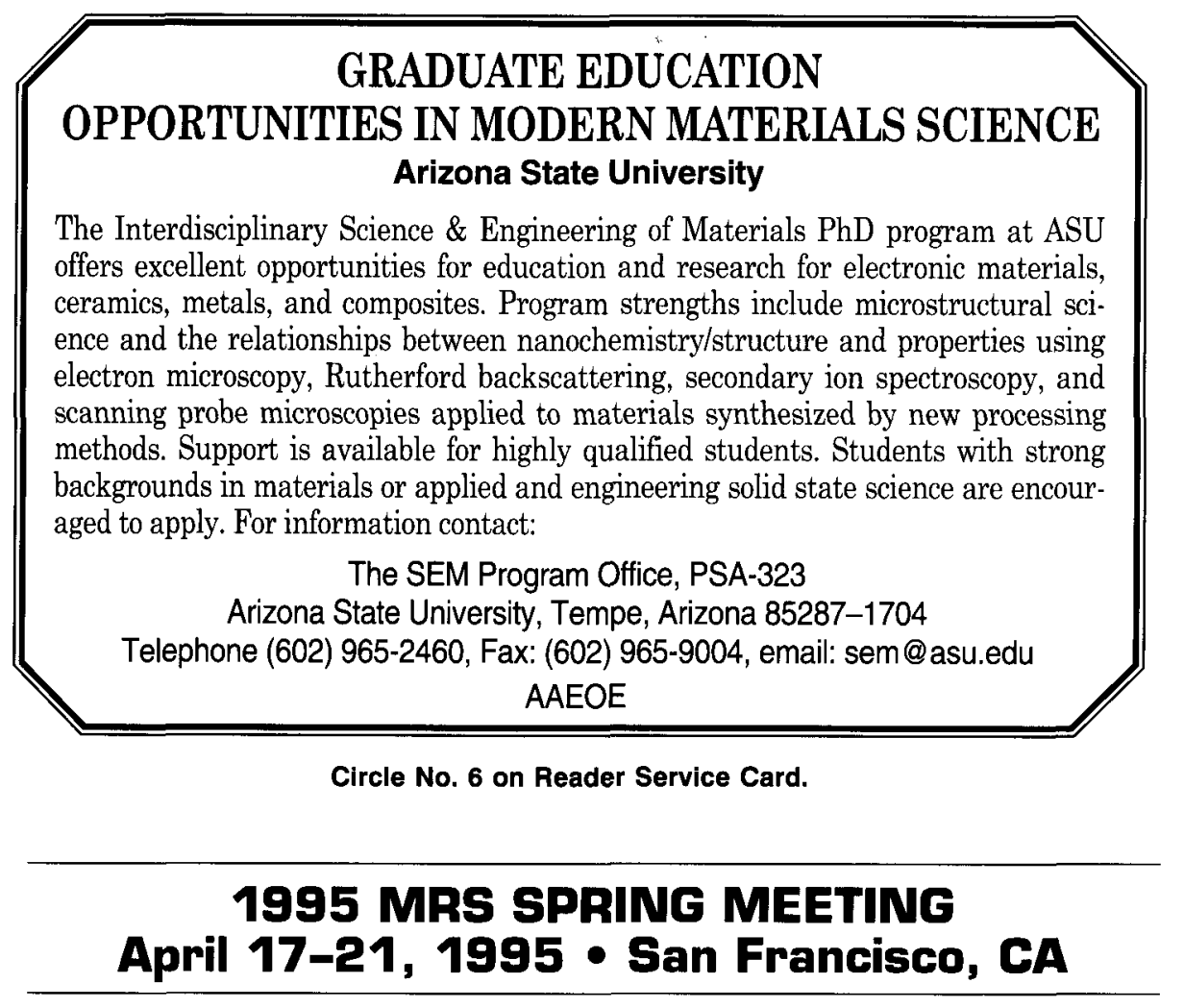

1949-51, then joined the metallurgy faculty at Yale, where he stayed until 1957. From 1957 through 1966, he was head of the Metallurgy group at IBM's T.J. Watson Research Center. He then joined Columbia University, where he is the Henry Marion Howe Professor Emeritus of Metallurgy and Materials Science in the Henry Krumb School of Mines.

In 1989 he received the Medal of the 9th International Conference on Internal Friction and Ultrasonic Attenuation in Solids. He is a Fellow of the American Physical Society and of TMS-AIME. Nowick has produced 160 publications spanning materials science and solidstate physics.

Nowick will receive his award Wednesday evening, November 30 at the 1994 MRS Fall Meeting during the Awards Ceremony. On Tuesday, November 29 at 9:30 a.m., Nowick will give a talk on "The Golden Age of Crystal Defects" in session 1U4, Essex West Room, Westin Hotel. He will review the period from 1949 to 1959 , when crystal lattice defects came of age and great advances were made in the study of both dislocations and point defects.

\section{NEW CVD Gases High Purity Methylsilane}

First reported as a precursor for heteroepitaxial silicon carbide on silicon, methylsilane has more recently been identified as the precursor to a plasma-deposited siliconcarbon-hydrogen polymer which can be used as a dry processable photoresist for high resolution applications. Available in limited quantities with $\geq 99.9 \%$ purity.

\begin{tabular}{|l} 
Other VOLTAIX \\
Products: \\
(Applications) \\
Germane, Digermane \\
(a-Si, heteroepi-Si) \\
Diborane, Phosphine \\
(BPSG, a-Si, epi-Si) \\
Silane, Disilane \\
(a-Si, epi-Si) \\
Trimethylboron \\
(BPSG, a-Si)
\end{tabular}

Other VOLTAIX Products: (Applications) Germane, Digermane (a-Si, heteroepi-Si) Diborane, Phosphine (BPSG, a-Si, epi-Si) Silane, Disilane (a-Si, epi-Si) (BPSG, a-Si)

\section{Deuterated Diborane and Trimethylboron}

Precursors for plasma deposited Tokomak wall passivation and impurity gettering coatings, in the international effort to develop hot fusion energy.

\section{Deuterated Silane}

Offered to improve the performance of silane derived silica for integrated optical waveguides.
For more information or to place an order

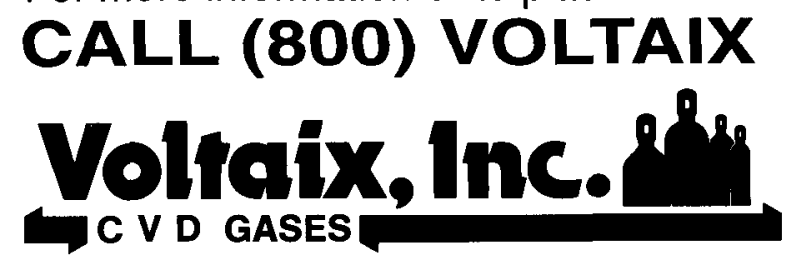

197 Meister Avenue • P.O. Box 5357 • N. Branch, NJ 08876 Fax: (908) 231-9063 - Telephone: (908) 231-9060 